\title{
Expanding Horizon of Transaction Cost in an Internet Based Business Platforms
}

\author{
Nitin Patwa \\ S P Jain School of Global Management \\ A. Seetharaman \\ S P Jain School of Global Management
}

The article focuses on the way the Internet has created a foundation for a large variety of new businesses that live on providing services lowering the transaction costs. Transaction theory its role and implication in changing industrial structure with a sprung up of the internet-based platform and understood how another theoretical framework could help in understanding changing economic environment. Airbnb (accommodation) and Uber (transportation) being among the prominent ones based on collaborative concepts, also termed as sharing economy are considered as base to explain the concept. The purpose of research is to understand the role of transaction cost and transaction cost theory in changing business environment of sharing.

Keywords: Transaction Cost, Sharing Economy, Transaction Cost Theory

\section{INTRODUCTION}

The internet-based platform has flourished in the past couple of years, eBay established before the dotcom crash whereas during past 5-10 years industries has seen various such establishment like Airbnb (accommodation) and Uber (transportation) being among the prominent ones based on collaborative concept also termed as sharing economy, sharing of resources for commercial and non-commercial basis. The article examines the development which is of commercial foundation and having significant economic reason and because of industrial structure. The article focusses transaction theory, its role, and implication in changing industrial structure with a sprung up of the internet-based platform and understood how another theoretical framework could help in understanding changing the business landscape.

The prominent explanatory framework is transaction cost theory as the digital platforms allow for decreasing transaction costs - such as in followings:

a) eBay case between sellers and buyers of all the items and services sold via eBay;

b) Airbnb case, between those who are offering and those buying accommodation;

c) Uber case, between those who are offering and buying transportation.

In the absence of digital platforms, the transaction costs of searching, contacting, and contracting would generally be much too high for such commercial markets to develop. However, this apparent 
explanatory framework has only been little elaborated upon academically and analytically (Benkler, 2004). This article aims to take a more analytical approach, using a transaction cost framework for examining prominent examples of the sharing economy. The examples examined are Airbnb and Uber. In 1937, Coase had his paper entitled 'The Nature of the Firm' (Coase, 1973) published. He used transaction costs as the explanation for the existence of firms: Were there no costs of transacting between the agents in markets, the structure of industries would be composed of individuals (or only small companies). The explanation for larger companies to be created is the existence of transaction costs, which can be minimized by the establishment of larger entities. His paper advances transaction costs as the primary basis for industrial structures with large companies, even discards other explanations, for instance, the divisions of labor and the specialization efficiency effects.

In this article, the transaction cost approach is a crucial element in explaining the development of sharing on a mass-scale. However, this approach cannot stand on its own. It does not explain the limits of the encroachment of sharing-services on established markets (e.g., hoteling and taxi driving). Inversely, it contributes to explaining the establishment of new large companies in the Internet world. There always have been companies that live on transaction costs. Business lawyers are good examples, as their function is to see to the contracting and enforcement of business agreements. So are real estate brokers, establishing the connections between the sellers and buyers of real estate property. However, the Internet has created a foundation for a large variety of new businesses that live on providing services lowering the transaction costs. It may be that some of the explanatory frameworks that Coase discarded so quickly, and other theoretical frameworks can offer elements of explanations for the structure of market developments. In this report, case analyses of the new Internet-based platform services, exemplified by Airbnb and Uber, are provided as well as an analysis of the implications for the markets they are addressing. Their analysis will get used for discussing theoretical approaches needed in order to explain these developments.

\section{LITERATURE REVIEW}

The concept of collaborative consumption (Hamari et al., 2013) propounded by Felson and Spaeth (Felson \& Spaeth, 1978) had a distinct meaning, specifically 'events in which one or more persons consume economic goods or services in the process of engaging in joint activities.' The paper provided examples such as 'drinking beer with friends, eating meals with relatives.'

Until 2007, there was not much research or publication available. However, in 2007, Russell Belk described sharing as an alternative form of distribution to commodity exchange and gift-giving. The author pointed out that sharing can foster community, save resources, and create specific synergies. His article addresses impediments to sharing as well as incentives that may encourage more sharing of both tangible and intangible goods (Belk, 2007).

In later publications, he provides a theoretical review of the concept of sharing and distinguishes 'sharing in' and 'sharing out' regarding gift-giving and exchange. He suggests that 'sharing in' dissolves interpersonal boundaries posed by materialism and possession attachment through expanding the aggregate extended self. However, such sharing gets challenged by growing market commoditization (Belk, 2010).

Sharing is a phenomenon as old as humankind, while collaborative consumption and the sharing economy are phenomena born of the Internet age'. He concluded by modifying the ancient wisdom, "You are what you own," converting it to new wisdom, "You are what you share," indicating that we were maybe entering the post-ownership economy (Belk, 2014). Later on Rachel Botsman and Roo Rogers have defined collaborative consumption as an activity which 'is enabling people to realize the enormous benefits of access to products and services over ownership, and at the same time save money, space, and time; make new friends; and become active citizens again'(Botsman \& Rogers, 2010).

\section{Transaction Cost}

Relatively few papers have studied transaction cost aspects of the sharing economy. Yochai Benkler in his essay 'Sharing Nicely' (Benkler, 2004) seeks to define a particular class of physical goods as 
'shareable goods' that systematically have excess capacity, and to combine comparative transaction costs and motivation analysis to suggest that this excess capacity may better get harnessed through sharing relations than through secondary markets. He pointed out that the primary systematic differences between the transaction costs of markets and sharing are related to information and enforcement costs. 'Markets use a combination of the price system and managerial hierarchical reporting and command flows to manage information about the universe of potential actions on resources in the world. Common frameworks use social cues that are usually less formal and less focused on crisply delineating the alternative courses of action open to participants in these frameworks' (Benkler, 2004). In regard to enforcement cost, he emphasizes that 'markets rely more heavily (though not exclusively) on formal enforcement, while social relations rely on informal enforcement mechanisms studied in the literature on social norms and reciprocity.'

\section{Profit Sharing}

There is always a discussion regarding non-profit and for-profit sharing - that the new for-profit sharing encroaches on already existing non-profit sharing. This consideration corresponds to the rise of numerous for-profit and non-profit businesses that are booming, all thanks to the rise of the sharing economy, for example, Airbnb and Uber. Neal Gorenflo talks about how money is ruining what started as a transformative concept. He emphasized that collaborative consumption is suffering from growing pains. 'As collaborative consumption goes mainstream, it risks losing the very thing that attracted people in the first place, the unique and even transformative social experiences made possible when you interact with helpful strangers' (Gorenflo, 2013). He stresses that this potential loss goes an essential part of the positive impact of non-profit sharing. Erin Griffith (Griffith, 2013) has a similar point of view. She provides examples of Airbnb, which took the model of Couch surfing and turned it into a for-profit enterprise, and car-sharing which is just a more organized car-pooling. She argues that a transaction that involves money is not sharing; it is renting or selling. At the same time, alternative approaches rise. Juliet B. Schor (Schor, 2014) points out that while the for-profit companies may be 'acting up,' these new technologies of peer-to-peer economic activity are potentially powerful tools for building a social movement centered on sound practices of sharing and cooperation in the production and consumption of goods and services. However, achieving that potential will require democratizing the ownership and governance of the platforms. Erin Griffith admits that without money many sharing economy sites would not have gotten to the size they are today. 'The sites required money to offer effective services and, as a result, their services have impacted more people than they might have otherwise. That is how, in most cases, for-profit sharing economy companies have outgrown their free counterparts' (Griffith, 2013).

New platforms such as Uber and Airbnb have driven significant criticism from established operators and concerns from governments about fair competition, workers' rights, and consumer protection. Brishen Rogers in his research focuses on the relationship between employment regulations and liberal distributive justice and the influence of information technology in the world of low-wage work. (Brishen, 2015) pointed out that 'Uber's longer-term impact on labor standards is quite unclear, however, and it may have dark implications for the future of low-wage work more generally.' He assessed Uber's effects on safety, privacy, discrimination, and labor standards and outlined how lawmakers might adapt existing laws to reach Uber and other ride-sharing companies.

The macroeconomic factors seem to play a vital role in driving the multifold growth of the sharing economy. Many researchers have pointed out that the new trend towards collaborative consumption started to gain momentum as a response to the global financial crisis and an attempt to fight overconsumption. According to a consultative body of the EU, collaborative consumption, such as car sharing, room rental, and digital communities for learning languages, represents great alternatives in times of crisis (EU, 2014). Many believe that the sharing economy is an appealing alternative for consumers due to its economic benefits (i.e., low cost, new income opportunities), which has been considered important following the global economic crisis. It also suggests that collaborative consumption will continue to grow even when the economy is fully recovered (Bardhi \& Eckhardt, 2012), (Walsh, 2011). 
The Internet has made it much easier for people to connect and to coordinate activities. People are now using platforms to rent, sell, or share things with others without the involvement of other agencies. It is self-explanatory approach, and many other researchers have suggested the importance of digital technologies, facilitating the emergence of sharing economy in overcoming the transaction costs, the trust and reputational barriers that once restricted sharing activities (Schor et al., 2015), (Stokes, et al., 2014), (Benkler, 2004), (Forum, 2014).

\section{Transaction Cost Theory and Theory on Substitution}

In this report, the theory of transaction costs is the basic explanatory framework for understanding the development of services like Airbnb and Uber. However, in order to understand the potentials for the costs of the transaction to influence the use of the new Internet-based platforms, the degrees of substitutability between traditional services and the new services have to be discussed. Two different but interrelated frameworks will briefly be dealt with: Transaction cost theory and the issue of substitution.

Transaction cost theory was first presented succinctly by Ronald Coase in his 1937 paper, 'The Nature of the Firm' (Coase, 1973). In the underlying assumptions in neoclassical economics, there is full information for all economic agents in all markets, and the only costs to be considered are the costs of production and transportation. There are no transaction costs, as all economic agents get well informed of qualities and prices of all products and all production and consumption possibilities.

What Coase did was to modify this assumption by including the real-world view that economic agents have only limited information, and that there are many costs associated with transacting in markets. This realistic view has a host of different implications for how markets work; however, Coase wanted to emphasize its implications for the industrial organization. He used it for explaining why we have firms, where many people co-operate in smaller or larger entities in the production and marketing processes, and not only a vast array of individual economic agents transacting with one another. The reason indicated was that because of the many different costs of transactions, economic agents would join up and create larger economic entities in order to lower transaction costs. However, he recognized that there are also costs of managing companies (internal transaction costs), but that the external transaction costs are powerful economic mechanisms that lead to the establishment of firms.

These initial ideas on transaction costs were later further developed, first and foremost, by Oliver Williamson (Williamson, 1981). Building partly on Herbert Simon's bounded rationality concept (Simon, 1957), Williamson developed a framework for understanding transaction costs, including the concepts of bounded rationality, uncertainty, opportunism, asset specificity, and transaction frequency. These are the kinds of factors that create transaction costs in the economy: The fact that there is uncertainty in markets and that all economic agents have bounded rationality and act opportunistically, and that assets to a large extent are specific and that transactions may take place frequently will create transaction costs.

Similar ideas and concepts are relevant for the discussions on substitution. In basic neoclassical economics, taking the foundational assumptions for granted, there is, in principle, full substitution between all products and services to the extent that different bundles of products and services can deliver utility to the users in ways that may satisfy the needs of users in similar manners. Substitution discussed products and services that fulfill the comparable needs of users. In our examples, hotels and private accommodation both deliver accommodation services and taxis, and private transportation both deliver transportation services. The discussion is the extent to which the different services are fully substitutable. Is there full substitution between hotels and private accommodation and between taxis and private transportation?

The answer to these questions can build on, e.g., a value proposition approach and an approach that takes into account the different reasons for transaction costs and the different elements in the business processes, where there are transaction costs. A hotel stay, for instance, offers a room and bed at some known standard quality (in most cases), solitude, several rooms at the same time if being a group of people, breakfast, etc. Private accommodation via Airbnb offers a room and bed at more unknown standards, the chance of meeting new people, etc. The value propositions are in no small extent similar, but also differ at some points. 
If looking at the issue from the reasons behind transaction costs and the processes of the transaction, uncertainty, bounded rationality, and opportunism may play a role, as the service users will have less knowledge on the services provided because of the lower degree of standardization. The processes of searching, contacting, contracting, etc. would previously be much more difficult for private accommodation and transportation than for hotels and taxis. However, this is precisely where the new digital platforms come in and change the underlying conditions for substitution. When it becomes easy to search for the right place or the right means of transportation, to contact and to contract for getting access to the services, the degree of substitution will increase. The potential substitutability between services becomes a real possibility for substitution.

\section{Internet-based Platforms}

With the diffusion of the World Wide Web from the mid-1990s, interest in categorizing the different types of new Internet-based business models was born. One of the first most cited contributions at the time was the paper 'Business models for the electronic market' by Paul Timmers (Timmers, 1998). Another significant contribution was the website maintained by Michael Rappa (Rappa, 2010), which included a taxonomical categorization of 'Business models on the Web.' This taxonomy included the following business model categories: Brokerage, advertising, infomediary, merchant, manufacturer, affiliate, community, subscription, and utility.

Later, during the first years on the new millennium, came an increasing interest in ontologies of business models, i.e., the interplay between the different elements of business models, including the technological and organizational aspects. One of the significant contributions in this field came from ICT researchers from the Netherlands and Belgium, see, e.g., (Faber et al., 2003) 'Designing business models for mobile ICT services.' Other significant contributions came from Alexander Osterwalder and Yves Pigneur, with Osterwalder's doctoral thesis, 'The business model ontology,' (Osterwalder, 2004) as a famous landmark.

The development of science in this field thus follows the traditional path from taxonomies to ontology - and back again with more specified taxonomies by increased knowledge on the interplay between the different elements and facets of business models. The interest in the present paper is on a type of brokerage model that not only has become the object of steeply increasing research attention during the past decade (Rochet \& Tirole, 2006); (Gawer \& Cusamano, 2002); (Hagiu \& Wright, 2011), but also has spread quickly in actual business developments, namely multi-sided platforms (MSPs).

The MSP concept is an extension of the two-sided market concept (Rochet \& Tirole, 2006) with more than two different kinds of customers, who are interdependent and are being served by the same platform. In the paper by (Hagiu \& Wright, 2011), they differentiate between MSPs, resellers and input suppliers, where MSPs get distinguished by the direct interaction between the different customer groups. In the two cases analyzed in the present paper, Airbnb organizes the direct interaction between accommodation providers and users and Uber organizes the direct interaction between transportation providers and users. Airbnb and Uber are thus two-sided markets - which may develop into multi-sided platforms, for instance, advertisers as a third kind of platform customers, if considered strategically desirable by the platform owners.

Airbnb and Uber are indeed not the first Internet-based platforms in the accommodation and transportation areas. Another commercial, as well as non-commercial platforms, have preceded them. In as well the accommodation and the transportation areas, there are many noncommercial platforms, where people can find free accommodation and transportation. These kinds of arrangements have contributed to the air of sharing, which the commercial platforms. However, while the non-commercial platforms are altruistic sharing platforms, the commercial platforms are 'in it for the money' both concerning the revenue derived by the platform owners and the payments to the accommodation and transportation providers.

Other commercial platforms have also existed before the large international ones with Airbnb and Uber as the archetypes. Renting accommodation, especially vacation accommodation, via agencies has been taking place for a very long time. The Internet has undoubtedly provided such commercial 
operations with a new and much more efficient platform but has, in many cases, basically been an extension of an existing business model. With Airbnb and Uber and other similar operations, these kinds of old-fashioned two-sided market operations moved to the international dimension. Airbnb and Uber have vastly extended the markets for residential accommodation and transportation.

As mentioned in the introduction to the paper, businesses living on transaction costs have existed 'as long as business itself like of Lawyers and real estate brokers. However, the Internet, with its vastly improved capabilities for communication between and among individuals and businesses establishes a basis for markets to expand and be created. The Internet allows for considerable decreases in transaction costs, but just for this reason, it also in a paradoxical manner creates the basis for new businesses based on handling transaction costs.

Airbnb provides an online platform that connects hosts who have places to rent with guests seeking to rent such places. The business has grown exceptionally it acquired several of its competitors and has surpassed the InterContinental Hotels Group and Hilton Worldwide as the world's largest room service provider. Airbnb states clearly in their 'Terms of Service, Host Guarantee Terms and Conditions' that Airbnb does not own, sell, resell, furnish, provide, rent, re-rent, manage, and control properties. Airbnb's responsibilities are limited to facilitating the availability of the site, application, and services and serving as the limited payment collection agent of each host to accept payments from guests on behalf of the hosts. Guests pay Airbnb when they book a place, and Airbnb releases the money to hosts 24 hours after the guest's check-in.

Airbnb charges hosts as well as guests for the use of the beerier online platform. Fees computed as a percentage of the applicable accommodation fee: Guests are charged a 6-12\% service fee on top of the reservation every time a reservation booked (Airbnb, 2015). The exact percentage of the guest service fee depends on the reservation subtotal. It falls steadily from $12 \%$ to $6 \%$ when the reservation amount gets increased so that guests can save money by booking large reservations. The company claims that fees cover the cost of running the Airbnb platform.

Hosts get charged 3\% of the per-night rate for every booking; the fee covers the cost of processing guest payments and is deducted from the host payout. Hosts are responsible for setting them per-night rates, cleaning fees, and security deposits. Hosts are responsible for following all laws and regulations, including paying any local taxes that apply to their accommodations.

The total fee may include taxes and cleaning fees. Airbnb charges VAT on its service fees for users (applicable to hosts and guests) from the European Union, Switzerland, Norway, Iceland, and South Africa. In some locations, Airbnb has made agreements with governments to collect and remit local taxes on behalf of hosts. Currently, Airbnb is collecting and remitting taxes in the following locations: Multnomah County and Portland, Oregon USA, San Francisco, CA USA, San Jose, CA the USA, Chicago, IL USA, District of Columbia USA, Malibu, CA USA, Amsterdam, NL.

If the guest pays for booking in a currency different than the one the host has chosen in the listing, the guest will be subject to varying Airbnb exchange rates, which may not be identical to the real-time market rate. Furthermore, Airbnb charges 3\% conversion/foreign transaction fees when booking gets done in foreign currency which accounts for Airbnb holding costs and currency risks. The conversion/foreign transaction fee is separate from and in addition to the Airbnb guest service fee. The conversion fee is applied to the reservation total after guest service fees get added (Airbnb, 2015).

Depending on the host, the actual costs can vary due to cleaning fees, extra guest charges, and security deposit. Moreover, it is challenging for guests to estimate the total costs during a searching process because of the variation in local tax levels, which makes the Airbnb pricing scheme less transparent than in the hotel industry.

Even though Airbnb has its own million dollars insurance policy, it is necessary to have a property owner's insurance. Airbnb will cover the property and general furnishings but only after the property's insurance policy is exhausted (Airbnb, 2015)

Even though Airbnb has left pricing decisions in the hands of hosts, they have recently started working on a predictive pricing algorithm. It will provide hosts with a recommended price for their space depending on many factors, including room style, property type, number of reviews, capacity, location, 
seasonality, pricing of other listings, hotel and airline demand, and even temperature changes at the destination. However, it still allows the host to set the final price ultimately.

Airbnb is a prominent example of a company that is part of the sharing economy. In 2014, Airbnb was named 'company of the year' by Inc. magazine, which claimed the year 2014 to be the year of the sharing economy (Fox, 2014). During the last few years, the company has grown exponentially but also has faced many problems with regulators concerning tax requirements and unfair competition.

\section{Present and Future Implications for the Hotel Industry}

A few years ago, nobody expected that the Airbnb platform would threaten the traditional hotel industry. Hotels have failed to predict the growing scale of Airbnb's activities. Airbnb's platform has scaled quickly regarding users and numbers of transactions. A strong network effect has influenced the constant growth of hosts and guests. Through its platform, Airbnb has not just created new user behaviors but has changed the supply side of the hotel industry as well.

Since 2014, big hotel chains have started realizing that the Airbnb platform is affecting their business, but it is tough for them to quantify the impact. Hotel News Now Report has examined how new platform businesses are impacting hotel demand, and, until 2014, luxury hotels have not considered Airbnb as a direct competitor. It has changed because Airbnb is expanding its offers into the business and luxury travelers' segments, which are critical groups of customers to the hotel industry. In 2014, Airbnb entered the business segment, teaming up with Concur - an American travel management company, providing travel and expense management services to businesses. The agreement with Concur allows Airbnb charges to appear directly on travelers' expense forms. By 2015, Airbnb reports that just below $10 \%$ of its guests are business travelers (Weed, 2015).

Even though Airbnb provides an alternative to traditional hotels, there is a new trend among small and luxury hotel owners who are joining the Airbnb platform to list their rooms alongside booking.com, trivago, and other websites. For example, the luxury hotel, Manhattan Club Apt, put an offer on the Airbnb website: Easter week: 4699 DKK per night.

Uber is a US-based online transportation network company founded in 2009. On December 4, 2014, Bloomberg announced that Uber was worth more than $\$ 40$ billion (Bloomberg, 2014). Uber does not own cars and does not employ drivers. Uber claims to be a marketplace where Uber's drivers as independent agents meet Uber's customers. Uber states in 'Terms and Conditions' that their services constitute a technology platform that enables users of Uber's mobile applications or websites to arrange and schedule transportation and/or logistics services with third-party providers of such services, including independent third-party transportation providers and third-party logistics providers under agreement with Uber or certain of Uber's affiliates (Uber, 2015).

Uber represents a platform business and provides more opportunities for the growth of a sharing economy. The core value that Uber delivers is a reduction of search and transaction costs for both drivers and passengers. The Uber platform is like an exchange platform because Uber creates value primarily by enabling direct exchange between actors. The Uber platform manages a network of drivers and passengers through apps and provides real-time ridesharing options. Uber also provides various options associated with transportation or logistics, including the transportation brands: Uber, uberX, uberXL, UberBLACK, UberSUV, and UberLUX and the logistics brands: UberRUSH, UberFRESH, and UberEATS.

Worldwide, the company now facilitates 1 million rides per day and is adding 50,000 new drivers per month. As of March 2015, the service was available in 55 countries and more than 200 cities worldwide (Uber, 2015). Uber, in contrast to Airbnb, is setting prices for rides. Payment is made directly to Uber, not to the drivers. Uber's commission-based pricing structure means that the company will take a percentage of the driver's profit every time the driver gives a ride. Uber fares include a base fee as well as rates based on time and mileage, which vary from city to city. UberX, for instance, charges $\$ 1.63$ per mile and $\$ 0.30$ per minute in Seattle, along with a $\$ 2.14$ base fare and a $\$ 6$ minimum fee. On average, $70-80 \%$ of gross fares go to independent drivers. Uber has stated that charges will be inclusive of applicable taxes where required by law. Some portion of the percentage that is retained by Uber goes to cover payment 
processing, payment fraud, refunds, customer service, dispute resolution, cellular handsets, and local regulatory efforts.

In 2012, Uber introduced a dynamic pricing scheme because there was a supply and demand imbalance during Friday and Saturday evenings. Uber offered the drivers higher prices during weekends. By offering more money to drivers, they were able to increase the road supply of drivers by $70-80 \%$ in Boston. Dynamic pricing changes are applicable when wait-times are increasing dramatically, and 'unfulfilled requests' start to rise. Prices get changed if utilization rates fall below $60 \%$ or are above $80 \%$ (Uber, 2013). There are two functions of the increased price model. One is to increase supply. The second function of the price increase is to reduce demand temporarily intentionally. Through these two mechanisms, the company can increase supply, assure reliability, which is a vital tenet of the company, and maximize the number of completed rides (Gurley, 2014). Uber has informed platform users that charges applicable in some geographical regions may increase substantially during times of high demand.

In 2014, Uber introduced a \$1 Safe Rides Fee, paid for by riders. The new fee, which applies nationwide, will cover the company's costs related to 'background checks, ongoing safety monitoring, education, insurance and safety features (e.g., an in-app emergency button).' This new fee is for UberX - which lets everyday drivers shuttle people around town - and not for the more expensive UberBLACK service, which uses professional chauffeurs (Soper, 2014).

On top of the Uber platform, other companies are trying to build their business models. Viewswagen has recently launched an advertising platform inside Uber and Lyft vehicles that allow drivers to show promotions on tablet screens in cars' backseats. It uses GPS to generate specific ads targeted toward passengers as they ride.

\section{Present and Future Implications for the Taxi Industry}

Uber, as the world's largest ride-hailing service operator, is directly affecting taxi companies' businesses. The taxi business is indeed sensitive to the fact that Uber and taxi drivers operate in the same markets subject to different rules like safety, privacy, and fares. Until now, taxi companies' response has been to demand more regulations for ridesharing. However, taking into consideration that $70 \%$ of the world's population is expected to live in urban areas by 2050 and face congestion problem, the viewpoint has been put forward that a better alternative for taxis and customers would be deregulation for both taxis and ridesharing (Beyer, 2015).

Felix Salomon has pointed out that Uber can raise taxi drivers' income over time, not lower them, due to the possibilities to sell their services to either taxi-fleet owners or companies like Uber. Looking from this perspective, more competition on the market means higher income for drivers (Salomon, 2013).

Presently, however, the Uber platform is disrupting the status quo of the taxi industry around the world. The San Francisco Municipal Transit Agency has noticed a sharp and steady downturn in taxi use in San Francisco from 1,424 average trips per month in March 2012 to 504 in July 2014, a steep 65\% decline (Agency, 2014). Uber already has and will increasingly have implications on the structure of the taxi industry, on jobs and wages.

Implications for theory and analysis

In a paper from 2014, Belk (Belk, 2014) seeks to align the concepts of sharing economy and collaborative consumption by characterizing the Felson and Spaeth definition and the definition by Botsman and Rogers (Botsman \& Rogers, 2010), which sees collaborative consumption as including 'traditional sharing, bartering, lending, trading, renting, gifting and swapping', as 'miss- specifications' (Belk, 2014). Belk (Belk, 2014), in contrast, seeks to promote a definition of collaborative consumption as 'people coordinating the acquisition and distribution of a resource for a fee or other compensation.'

Such a definition puts collaborative consumption on par with the commercial versions of sharing. One of the most prominent discussions on sharing and collaborative consumption is on the commercial versions and aspects (for-profit) vs. the non-commercial (non-profit) versions and aspects. The criticism got raised against the commercial versions for piggy-backing on all the non-commercial initiatives, where people share resources without charging any fees. Another line of inquiry is represented by, for instance, Rifkin (Rifkin, 2014), who, in his book on 'The zero marginal cost society' among a multitude of other 
issues, also writes about the sharing economy. The fundamental thought of the book is that in a growing part of the central sectors of society, there is a trend towards zero marginal costs. The clearest example is information and communication where the marginal costs of one additional person using a piece of information or communicating are (at least close to) zero (Rifkin, 2014).

This article does not venture into such a discussion but stays with the shorter term (and maybe more realist) industrial organization implications of the sharing economy trends. These implications mainly relate to the issues of transaction costs, substitution (and complementation), and multi-sided markets. The lowering of transaction costs facilitated by Internet-based platforms allows for the exchange of goods and services between people that would not otherwise have been possible - just because of the very high costs of searching, contacting and contracting that this would require. Uber's and Airbnb's are becoming large business operations, where there formerly were no possibilities for such operations to get erected. At the same time, these new markets and market operators also substitute for existing business operations. As the new markets and operators do not service entirely new human needs (e.g., accommodation and transportation), there is a degree of substitution - but also complementation.

The examples of Uber and Airbnb discussed in this report show that there can be a relatively large degree of substitution and a much-derided competition between the old business models and the new ones. It is not likely, however, that the new business models in foreseeable time will entirely eradicate the old models (e.g., hoteling and taxi driving). However, they can do serious harm to the existing business models. Moreover, the question raised by Rifkin (Rifkin, 2014) is whether just a share of the market for the new operators will be able to tip the market in favor of the new operators. $10 \%$ is the figure cited by Rifkin. The reason should be that the margins in some industries are low and that losing just a share of the turnover may cause the market to tip.

It is, however, is a slightly strange argument, as it presupposes that the existing industries are not able to adapt and shrink if needed. The most likely scenario is that there will be a degree of substitution, but also a degree of complementation - on the demand side as well as the supply side. On the demand side, the new operators may attract users that did not previously use the services of the existing industries. On the supply side, as is shown concerning hoteling as well as taxi driving, some of the existing operators may offer their services through the new platforms. Furthermore, it is not only a struggle between incumbents and newcomers. The disruption of markets also leads to incumbents entering the markets of other incumbents. Once a relatively stable division of labor is shaken up in one industry, and it will have repercussions in some surrounding industries.

In discussions on the sharing economy, many different trends and issues are now and then blended. It applies, for instance, to mixing the sharing economy issue with the presently trendy concept of cocreation (Prahalad \& Ramaswamy, 2004). There is co-creation in the sharing of facilities. However, the focus of the co-creation issue is different from the issue of sharing. Co-creation is about the joint creation of value and also of innovation (Sundbo et al., 2015) in the interaction between providers and users, while the commercial aspects of the sharing economy are primarily about the creation of new markets. Also, it is about the creation of new companies providing the platforms for the exchange of goods and services the companies living on transaction costs.

In order to analyze these new sharing developments, we suggest using an analytical framework comprising theories on multi-sided platforms, transaction costs, and substitution and complementation. The new commercial sharing platforms are either two-sided markets or may develop into multi-sided markets. The primary function of such platforms is to deal with the transaction cost issue that has previously hindered such markets from developing to any great extent. The new markets will, to different degrees, substitute for existing providers and business models but will also enter an interaction with existing business models in a complementary manner. 


\section{CONCLUSION}

Current discussions in public media on issues relating to the sharing economy are mostly very enthusiastic. The new ways of sharing and transacting goods and services or somewhat critical concerning commercial sharing arrangements and businesses 'piggy-backing' on the non- commercial activities and concerning labor conditions for those delivering the services and service quality for those receiving the services being downgraded - or rather the conditions for those working in the traditional industries being undermined by the newcomers. These are critical issues and will also, in different manners, affect the industrial developments and structures, for instance, regulatory measures promoted by the taxi industry in order to defend the working and service conditions in traditional taxi businesses - and protect the existing markets from new entrants.

In the report, we focussed on the implications for the industrial structures in the affected industries. The research question asked concerned with the extent to which transaction cost theory can be used to explain the changing industrial structures in the application areas that the Internet-based platforms are addressing and how other theoretical frameworks can help understand these developments.

The conclusion is that transaction cost theory is a central theoretical tool to understand the sharing economy. Internet-based platforms facilitate drastic reductions in the transaction costs between users and providers of, for instance, private accommodation and transportation. It creates whole new markets, which were previously only possible to a minimal extent. However, these new markets also substitute for existing accommodation and transportation markets. Theories regarding substitution and complementation must thus get added to transaction cost theory in order to analyze industrial developments. As has been shown with the Airbnb and Uber cases, there is not only substitution but also complementation.

An obvious question could be whether the new business models will entirely substitute for the old ones. The degree of the substation is subject to detailed analyses in the different industries, but it seems that there could be considerable possibilities for substitution based partly on lower prices of the new sharing arrangements. However, there are also limitations, which are related to the fact that there are differences in value propositions, for instance, between a hotel room and private accommodation. Limitations are also related to the regulatory measures that will get taken about the new business models, but also the adaptability of the existing industries and their competitive capabilities.

An interesting side effect is that the reduction in transaction costs is facilitated by business operations that, in some cases, become exceptionally highly valued huge international business companies. The reduction in transaction costs, which leads to increased possibilities for smaller business operations to function, at the same time leads to the creation of large business companies thriving on transaction costs. It is, in a sense, a paradox, which also bears witness to the strength of the capitalist economy. Rifkin (Rifkin, 2014) advances the idea that zero marginal costs will undermine the capitalist economy. However, the information and communication industries, which are core examples of the 'zero marginal cost economy,' have shown the high adaptability of the capitalist economy. The industries thriving on transaction costs underline this.

The platforms that facilitate the lowering of transaction costs create two-sided markets or develop into multi-sided platforms. These kinds of business models become increasingly widespread, facilitated by the Internet. By the abovementioned different theoretical approaches, the report proposes a theoretical framework for analyzing the sharing economy based on theories on multi-sided platforms, transaction costs, and substitution and complementation.

\section{ACKNOWLEDGEMENT}

Authors will like to thank for the contribution of Astha Goswami, Rahul Gadia, Dilip Mane, Vinay Sohani, Sushil Hinge from S P Jain School of Global Management. 


\section{REFERENCES}

Bardhi, F., \& Eckhardt, G. M. (2012). Access-based consumption: The case of car sharing. Journal of Consumer Research, 39(4), 881-898.

Belk, R. (2007). Why not share rather than own? The Annals of the American Academy of Political and Social Science, 611(1), 126-140.

Belk, R. (2009). Sharing. Journal of Consumer Research, 36(5), 715-734.

Belk, R. (2014). You are what you can access: Sharing and collaborative consumption online. Journal of Business Research, 67(8), 1595-1600.

Benkler, Y. (2004). Sharing nicely: On shareable goods and the emergence of sharing as a modality of economic production. Yale LJ, 114, 273.

Beyer, S. (2015). How To Solve The Uber vs. Taxi Conflict? Medallion Reform. Retrieved from Forbes.

Bloomberg. (2014). Uber Valued at \$40 Billion in \$1.2 Billion Equity Funding. Retrieved from Bloomberg terminal.

Bloomberg. (2015). Airbnb Said to Be Raising Funding at \$20 Billion Valuation. Retrieved from Bloomberg terminal.

Botsman, R., \& Rogers, R. (2011). What's mine is yours, how collaborative consumption is changing the way we live?

Brishen, R. (2015). The social costs of Uber. University of Chicago Law School, Chicago, Illinois, USA. [Google Scholar].

Coase, R. (1973). The nature of the firm. Economica, 4(16), 386-405.

EU. (2014). EU advisory body calls for more collaborative consumption. Retrieved from http://www.euractiv.com/health/eu-advisory-committee-calls-coll-news-532944

Faber, E., Ballon, P., Bouwman, H., Haaker, T., Rietkerk, O., \& Steen, M. (2003, June). Designing business models for mobile ICT services. In Workshop on concepts, metrics \& visualization, at the 16th Bled Electronic Commerce Conference eTransformation, Bled, Slovenia.

Felson, M., \& Spaeth, J. L. (1978). Community structure and collaborative consumption: A routine activity approach. American Behavioral Scientist, 21(4), 614-624.

Forum, T. (2014). The Sharing Economy. TRPC.

Fox, M. (2014). Airbnb named Inc. 's company of the year. Retrieved from MFoxCNBC http://www.cnbc.com/id/102217146

Gawer, A., \& Cusamano, M. (2002). Platform leadership: How Intel, Microsoft and cisco drive industry innovation. Harvard Business School Press.

Gorenflo, N. (2013). Collaborative Consumption is Dead, Long Live the Sharing Economy.

Griffith, E. (2013). Does money taint the sharing economy? Retrieved from http://pando.com/2013/03/14/does-money-taint-the-sharing-economy/

Gurley, B. (2014). A Deeper Look at Uber's Dynamic Pricing Model. Retrieved from Above the Crowd http://abovethecrowd.com/2014/03/11/a-deeper-look-at-ubers-dynamic-pricing-model/

Hagiu, A., \& Wright, J. (2011). Multi-sided platforms. Harvard Business School Working Papers.

Hamari, J., Sjöklint, M., \& Ukkonen, A. (2013). The sharing economy: Why people participate in collaborative consumption. Working Paper.

Osterwalder, A. (2004). A business model ontology: A proposition in a design science approach. Université de Lausanne. Université de Lausanne.

Prahalad, C. K., \& Ramaswamy, V. (2004). Co-creation experiences: The next practice in value creation. Journal of Interactive Marketing, 18(3), 5-14.

Rappa, M. (2010). Business Models on the Web. Retrieved from http://digitalenterprise.org/models/models.html.

Rifkin, J. (2014). The zero marginal cost society: The Internet of things, the collaborative commons, and the eclipse of capitalism. Palgrave Macmillan.

Rochet, J., \& Tirole, J. (2006). Two-sided markets: A progress report. The RAND Journal of Economics, $37(2), 645-667$.

196 Journal of Applied Business and Economics Vol. 21(6) 2019 
Salomon, F. (2013). Reuters. Retrieved from Why cab drivers should love Uber http://blogs.reuters.com/felix-salmon/2013/12/11/why-cab-drivers-should-love-uber/

Schor, J. (2014). Tellus Institute. Debating the Sharing Economy. Retrieved from The Great Transition Initiative http://www.greattransition.org/

Schor, J., \& Fitzmaurice, C. (2015). Collaborating and Connecting: The emergence of the sharing economy. In J. F. Schor, Handbook on Research on Sustainable Consumption. Cheltenham Edward Elgar, UK.

Simon, H. (1957). Models of man: Social and rational. New York: John Wiley and Sons.

Soper, T. (2014). Retrieved from UberX adds \$1 'Safe Rides Fee' for passengers, reinstates 20\% commission fee for drivers http://www.geekwire.com/2014/uber-adds-1-safe-rides-feepassengers/

Stokes, K., Clarence, E., Anderson, L., \& Rinne, A. (2014). In Kathleen Stokes, Emma Clarence, Lauren Anderson, April Rinne, Making sense of the UK collaborative economy. Nesta and Collaborative Lab.

Sundbo, J., Sundbo, D., \& Henten, A. (2015). Service encounters as bases for innovation. The Service Industries Journal, 35(5), 255-274.

Timmers, P. (1998). Business models for electronic markets. Electronic Market, 8(2), 3-8.

Uber. (2013). System and Method for Dynamically Adjusting Prices for Services. Patent No: US 2013/0246207A1 by Uber Technologies Inc.

Walsh, B. (2011). Today's smart choice: Don't own. Share. Time International, 1(3), 49.

Weed, J. (2015). Airbnb grows to a million rooms, and hotel rivals are quiet, for now. The New York Times, 11.

Williamson, O. E. (1979). Transaction-cost economics: the governance of contractual relations. The Journal of Law and Economics, 22(2), 233-261.

Williamson, O. (1981). The economics of organization: The transaction cost approach. The American Journal of Sociology, 87(3), 548-577.

Zervas, G., \& Byers, J. (2013). The rise of the sharing economy: Estimating the impact of Airbnb on the hotel industry. Boston University School of Management Research Paper Series, no. 2013-16, 36. 